\title{
Edith Stein em diálogo com Hedwig Conrad-Martius na interpretação da teoria do evolucionismo
}

\section{Edith Stein in Dialogue with Hedwig Conrad-Martius in the Interpretation of the Theory of Evolutionism}

\section{Adair Aparecida Sberga*}

\begin{abstract}
RESUMO
Edith Stein, pesquisadora sobre o conhecimento do ser humano e sua formação, amplia suas abordagens e conhecimentos na análise e discussão com outros teóricos. Dentre esses, confrontase com Hedwig Conrad-Martius, bióloga de grande projeção por suas investigações e publicações, que procuram integrar a pesquisa científica à investigação filosófica, no intuito de olhar a realidade global da natureza para descrever suas origens, estruturas e processo vital. Em seu texto Potência e Ato, Stein se confronta com Conrad-Martius, a partir da sua obra Diálogos Metafísicos e, por meio da sua interpretação e análise crítica, avança na compreensão das dimensões constitutivas da estrutura do ser humano ao compará-lo com os outros seres da natureza. Nesse percurso se depara com a teoria do evolucionismo e, em concordância com Conrad-Martius, afirma que essa deve ser tratada somente como teoria interpretativa e não como verdade, porque muitas das suas afirmações não podem ser comprovadas.
\end{abstract}

Palavras-Chave: Edith Stein. Hedwig Conrad-Martius. Diálogos Metafísicos. Teoria do Evolucionismo.

\begin{abstract}
Edith Stein, who is a human knowledge researcher and its formation, broadens her approaches and concepts in analysis and discussion with other theoreticians. Among those, she is compared to Hedwig Conrad-Martius, a very prominent biologist, whose investigation and publications aim to match the scientific research to philosophical survey and publications, by intending to watch the global reality of the nature in order to describe its origins, structures and vital process. In her text, Power and Act, Stein is compared to Conrad-Martius, from her work Metaphysical Dialogues and, through her interpretation and critical analysis, she goes ahead in the comprehension of the dimension that constitute the structure of the human being when it is compared to the other beings in nature. In this course, she faces the theory of evolutionism and in consonance with Conrad-Martius, she declares that it should be treated only as an interpretative theory, not as truth, because many of her statements cannot be proved.
\end{abstract}

KEYwords: Edith Stein. Hedwig Conrad-Martius. Metaphysical Dialogues. Theory of Evolutionism.

\footnotetext{
* Mestre em Educação pela Università Pontificia Salesiana (UPS - Roma/Itália). Doutora em Ciências no Programa de Psicologia da Universidade de São Paulo (USP-RP). Diretora Executiva da Rede Salesiana de Escolas e Vice-Presidente da Associação Nacional da Educação Católica. E-mail: <adair.sberga@rse.org.br>.
} 


\section{INTRODUÇÃO}

Edith Stein (1891-1942), filósofa interessada no conhecimento do ser humano e discípula do fenomenólogo Edmund Husserl, realiza muitas pesquisas, debates e confrontos com teóricos de sua época. Uma dessas investigações se dá a partir dos escritos da bióloga Hedwig Conrad-Martius, durante o período em que Stein produz sua obra Potência e Ato (1931), deixando evidente o quanto valoriza as concepções, análises e pesquisas da bióloga. Além disso, Stein deposita confiança em seus procedimentos teóricos e metodológicos e se apropria de muitas de suas colocações que lhe permitem avançar na compreensão da especificidade da pessoa humana, em confronto com a teoria do evolucionismo. Essa confiança se dá de forma explícita quando Stein pede a Conrad-Martius para que leia o que está produzindo em Potência $e$ Ato e lhe ofereça um veredicto sobre a mesma, o que, na verdade, a bióloga nunca pode fazer por falta de tempo e saúde. No entanto, como Stein tem um pensamento autônomo e crítico, também é capaz de conceber aquilo que pode parecer contraditório nos escritos de Conrad-Martius e aquilo que contribui para uma maior completude e profundidade na busca da verdade sobre o ser humano, em comparação aos outros seres da natureza.

Como Conrad-Martius é uma autora pouco conhecida no cenário brasileiro, a seguir serão apresentados alguns de seus traços biográficos, que mostram em uma visada a extensão de suas pesquisas e escritos. Em seguida, serão abordadas algumas análises e discussões sobre natureza, matéria e espírito, ciência, metafísica e evolucionismo, interpretadas por Stein em Potência e Ato, a partir daquilo que a bióloga coloca em sua obra Diálogos Metafísicos.

\section{ASPECTOS GERAIS SOBRE HEDWIG CONRAD-MARTIUS}

Hedwig Conrad-Martius nasce em 1888, em Berlim. Estuda história e literatura na Universidade de Rostock e depois frequenta cursos de filosofia, psicologia e história da arte em Munique e em Göttingen, sendo que por quatro semestres frequenta aulas de Husserl e Reinach. De 1911 a 1912 torna-se presidente da Sociedade filosófica de Göttingen e neste último ano obtém o prêmio da Faculdade de Filosofia de Göttingen com o ensaio Die erkenntnistheoretischen Grundlagen des Positivismus (Os fundamentos do Positivismo). Forma-se em Munique e se casa com Theodor Conrad (1881-1969). Em 1916, publica o ensaio Zur Ontologie und Erscheinungslebre der realen Aussenwelt (Para uma ontologia e uma doutrina do modo em que aparece o mundo exterior), no Jahrbuch für Phänomenologie und phänomenologische Forschung, vol. III, dirigido por Husserl. Em 1921, publica o extenso ensaio Realontologie (Ontologia do real), no vol. VI, do Jahrbuch.

Durante mais de uma década, de 1921 a 1934, Conrad-Martius continua suas pesquisas e escreve ensaios que se versam sobre o tema da Ontologia universal; dentre esses escreve Metaphysische Gespräche (Diálogos Metafísicos) e também profere conferências. Nesse último ano, incentivada pela sua convivência com o mundo vegetal, escreve Die Seele der Pflanzen (A alma das plantas).

Em 1937, transfere-se para Munique e no ano seguinte escreve o livro Ursprung und Aufbau des lebendigen Kosmos (Origem e estrutura do cosmos vivo). Em 1944, publica a obra Der Selbstaubau der Natur (A autoconstituição da natureza). No período em que foi obrigada a se refugiar em Arnstorf, de 1948 a 1949, escreveu Wissenschaftlichmetaphysische Perspektiven (Perspectivas cientifico-metafísicas), Bios und Psyche 
(Vida e Psique) e Abstammungslebre (Evolucionismo). Nesse último ano torna-se professora na Universidade de Munique.

De 1951 a 1957, recebe algumas honrarias públicas, tornando-se membro do Conselho da Academia Tutzing e professora honorária da Universidade de Munique. Neste tempo escreve dois importantes livros Die Zeit (O Tempo) e Das Sein (O Ser). No ano seguinte, é condecorada com a Cruz ao mérito da República Federal Alemã e publica Der Raum ( $O$ espaço). No período de 1959 a 1963, cuida da edição das cartas recebidas de Edith Stein e publica seu livro Die Geistseele des Menschen (A alma espiritual do homem). De 1963 a 1966, seu discípulo Eberhard Avé-Lallemant cuida da edição dos seus escritos de filosofia e o publica em três volumes na Schriften zur Philosophie (Revista de Filosofia).

Conrad-Martius falece, em Munique, no dia 15 de fevereiro de 1966.

\section{REFERÊNCIAS DE STEIN À OBRA DIÁLOGOS METAFÍSICOS DE CONRAD-MARTIUS E A CONCEPÇÃO DE MATÉRIA E ESPÍRITO}

Desde 1917, têm-se notícias do interesse de Stein por pesquisas que se referem ao ser humano e à natureza. Em sua obra Introdução à Filosofia, aborda questões sobre a epistemológica e sobre a filosofia da natureza. Em Potência e Ato, Stein retoma esse último tema e o interpreta relacionando-o com a obra Diálogos Metafísicos, de ConradMartius. Constata algumas divergências nessa obra, mas ao mesmo tempo está certa de que as concepções da bióloga vão muito além do que se pode colher nesse único escrito.

Stein inicia a discussão sobre essa obra abordando a temática da metafísica e procura compreender e relacionar o que é matéria, alma e espírito. Posteriormente também aprofunda questões referentes à antropologia e à interpretação da natureza, que para ela se caracteriza como natureza vivente.

Enquanto na obra, Conrad-Martius tende a diferenciar o material do espiritual (um vem de baixo e o outro vem do alto) e distinguir alma de espírito, Stein ao contrário, faz conexões, junção sem separação, entre essas dimensões: o espírito está presente em toda a realidade, também a matéria enquanto matéria formada tem uma dimensão espiritual, tem um sentido, assim como a alma humana tem um aspecto espiritual que caracteriza e atribui uma especificidade ao ser humano.

No entanto, também Conrad-Martius admite um conceito alargado de alma e do mesmo modo de Stein, que se baseia em Edmund Husserl e Tomás de Aquino, concebe que a alma está presente nos seres humanos e, ainda, nas plantas e nos animais.

Para Conrad-Martius, a peculiaridade da alma é ser o centro da vida e, devido a isso, concebe à alma um sentido que se aproxima das concepções aristotélico-escolástica, as quais também admitem que as plantas, os animais inferiores e os espíritos superiores são dotados de alma. Assim, a alma é um fundamento que qualifica o ser vivente e Conrad-Martius afirma que "somente o animal superior que começa a habitar na sua profundidade qualificante e a viver e a agir pessoalmente fora dela, tem uma alma em sentido significativo". O animal, que tem corpo pessoal e vida pessoal, pode comandar o seu próprio corpo, porque a sua sede central não está no corpo, mas na sua alma, no entanto, o animal inferior não tem alma pessoal. A planta tem corpo vivente, mas não tem corpo pessoal, porque não tem domínio sobre si mesma, então, sua alma é impessoal. Nesta distinção entre alma pessoal e impessoal, só o ser humano tem alma pessoal.

STEIN, E. Potenza e Atto, p. 247. 
A sede do animal está em sua alma, mas a sede do ser humano, ao contrário, é transportada para o espírito (Geist). O que caracteriza a essência desta sede do espírito é ser despojada de Si mesmo, desfazendo-se da fixação de um Si determinado e vinculado (aprisionado), sendo livre no espírito e com o espírito. O elevar-se ao espírito torna o ser humano livre e senhor não só do seu centro psíquico, mas diante do seu próprio espírito. O ser humano que nasceu de modo natural e não espiritual, assume-se como pessoa que vem de "baixo", mas para que possa assumir-se enquanto pessoa a partir de baixo, deve assumir a sua liberdade no espírito a partir do "alto". Deste modo tanto o seu espírito, quanto a sua alma têm a característica de ser pessoal e livre. Continua Conrad-Martius

Aquele lugar da liberdade absoluta, aquele lugar do livre nascimento do eu ou da constituição do eu é [...] necessariamente o portão metafísico aberto através do qual o espírito de Deus pode passar livremente. O ser humano tem o seu espírito próprio, o qual tem origem na profundidade do seu ser singular pessoal; mas este espírito, através do espírito de Deus, pode ser transfigurado e elevado ao absoluto [...] É possível exprimir-se assim só lá onde a alma do ser humano esteja no espírito e resulte do espírito ou esteja assegurada nele. ${ }^{2}$

Na tentativa de descrever qual é a essência do espírito, a bióloga explica que esse se revela como aquele que respira, assim, sua característica é espirar e inspirar, ou seja, "fazer-se espírito" e "fazer-se corpo vivente", compreendendo com isso algo que pode se dar de modo completamente inconsciente e não desejado, mas algo que também é possível como "espírito objetivo". Nesse, trata-se de uma alma natural, impessoal, mas que é qualificante, porque dá a vida.

Stein avança nessa concepção e para ela a alma também é o que qualifica o ser humano, mas há algo que o qualifica de modo ainda mais específico, que o individualiza de modo pessoal e profundo. Esse algo, que brota da raiz da própria alma, que não se pode "exprimir com qualidades definíveis"” é o seu núcleo (Kern) ou como define Stein é a "alma da alma"4 Essa é totalmente individual, indissolúvel e inominável"5, tamanha a sua originalidade, e vive na profundidade da alma, ou seja, na interioridade do ser humano.

Para Conrad-Martius, a pessoa dotada de corpo, alma e espírito também pode ter um núcleo, no qual fundamenta o ser da sua vida atual. Esse núcleo não se atualiza totalmente, mas em linha de princípio pode se tornar atual como um inteiro. A bióloga chega a essa qualificação específica da alma, que não se encontra nem plantas nem nos animais, e explica isso como algo que provém não de uma matéria, mas do alto. Ela dá um salto quando propõe essa explicação e Stein acredita que é preciso de mais fundamento para se chegar a essa conclusão. Então, há um confronto entre Stein e Conrad-Martius, que se desenvolve a partir de uma das abordagens mais importantes proposta por essa bióloga, que é a questão da compreensão da teoria do evolucionismo.

Conrad-Martius admite que a alma humana, com essa sua singularidade qualificante, provém do alto, isto é, ela não concebe o ser humano como um produto da atividade evolutiva da natureza, mas como uma obra da intervenção extraordinária do Criador, porque se Deus cria tudo, cria também a matéria e esta, por sua vez, não pode produzir o espírito, mas somente almejar de possuí-lo. Em sua obra Diálogos Metafísicos expressa,

${ }^{2}$ STEIN, E. Potenza e Atto, p. 249.

${ }^{3}$ STEIN, E. Psicologia e Scienza dello Spirito, p. 249.

${ }^{4}$ ALES BELLO, A. Prefazione, p. 11.

${ }^{5}$ STEIN, E. Potenza e Atto, p. 249. 
mais especificamente, que o ser humano tem um duplo ser e correspondentemente um duplo nascimento. Assim se explica: "[o ser humano] gerado e formado pela qualificante falta de fundamentos e causas primeiras da natureza, ele nasceu, ao mesmo tempo, do 'espírito', passando a existir, assim, pessoalmente, tanto a partir do baixo, quanto do alto"6. E ainda completa afirmando

O ser humano, aqui, ser humano é 'ser de nascimento natural e não de nascimento espiritual'; ele se assume completamente e absolutamente a partir de baixo, mas até que possa assumir-se enquanto pessoa a partir do baixo, deve assumir a sua liberdade no espírito a partir do alto. Neste modo, sua pessoal e livre propriedade não advém só do seu espírito, mas também da sua alma. Assim, torna-se capaz de conduzir sobre a luz e a liberdade tudo o que vive e exprime no obscuro de sua alma. [...] Se foi dito que a divindade trina habita pessoalmente na alma do ser humano, isso não pode valer para a alma natural. É possível exprimir-se assim só lá onde a alma do ser humano esteja no espírito e resulte do espírito ou esteja nesse assegurada. ${ }^{7}$

A partir dessa visão, Stein capta nos Diálogos Metafísicos um dualismo platônico e neo-platônico, que ela não aceita e denuncia. Para Stein, o ser humano, não tem um duplo nascimento, e não é formado a partir de uma dualidade (corpo mais espírito). Se assim for, a matéria deve ser concebida como um "nada" (em relação ao aspecto formal ${ }^{8}$ ), é um "fundamento obscuro", que precisa ser elevada por outro e, a partir dessa visão, há a suspeita de que a matéria não deriva de Deus. Para Stein, o ser humano, como ser livre e pessoal, não tem um início em Deus diferente das outras criaturas ${ }^{9}$. O ser humano é formado ao mesmo tempo como matéria e forma, que se unem em uma totalidade indivisível.

No entanto, os que conhecem profundamente os pensamentos da Conrad-Martius sabem que ela não sustenta esse dualismo e a Stein sabe que não é esse o pensamento da bióloga, mas talvez na obra falta uma justificativa teorética mais convincente. Por isso, Stein rebate essa concepção, que parece ser dualista, com a concepção aristotélicatomista que não concebe dualidade entre matéria e espírito.

Na opinião de Stein, o ser humano, como todos os outros seres, enquanto ligado ao ser divino lhe é próprio um ser que vem do "alto" e enquanto ligado à natureza lhe é próprio um ser que vem de "baixo". Então, como a natureza possui a sua origem na matéria atualizada por meio do espírito divino, para a Stein a origem de todo ser envia em último plano "para o alto", para o ato criativo de Deus. A base para fundamentar essa concepção de Stein, presente em Potência e Ato, é uma discussão entre o platonismo, o aristotelismo e o tomismo, confrontados pela Stein sob a trilha da escola fenomenológica, tendo como grande tema a relação entre essência e existência, na delimitação entre metafísica e gnoseologia.

Para auxiliar na compreensão dessas discussões é necessário adentrar com mais dados na interpretação sobre a natureza, colocada pela bióloga, e averiguar como se dá a conexão entre ciência e metafísica.

\footnotetext{
${ }^{6}$ STEIN, E., Potenza e Atto, p. 35.

${ }^{7}$ STEIN, E., Potenza e Atto, p. 249.

${ }^{8} \mathrm{O}$ aspecto formal se refere ao aspecto potencial que gradativamente se desenvolve segundo a sua forma.

${ }^{9}$ Segundo estudiosos de Conrad-Martius, isso também é verdadeiro para ela, já que essa bióloga também concebe o aspecto material como o desenvolvimento direcionado para a luz. Pode ser que essa compreensão não esteja tão explicitada nessa obra específica da qual Stein está tratando.
} 


\section{INTERPRETAÇÃO SOBRE A NATUREZA E O ACORDO ENTRE A CIÊNCIA E A METAFÍSICA}

A contribuição original das pesquisas de Conrad-Martius se refere a sua interpretação sobre a natureza e o seu interesse é o de estabelecer um acordo profundo entre a pesquisa científica e a investigação filosófica. Nesse sentido, adota como fio condutor o "realismo" que consiste no fato de "reconhecer uma realidade 'substancialmente' configurada numa pluralidade de modos que podem referir-se na sua totalidade a alguns "princípios fundamentais" "' 10 Sua analise visa descobrir o sentido da materialidade, entendida como aquilo que existe realmente ou substancialmente.

O que Conrad-Martius quer demonstrar, com originalidade, é que algo pode ser real não só porque aparece ou tem uma substância própria, mas no sentido de que também é "material". A unidade da coisa está na própria coisa ou na forma da sua existência e tudo se demonstra pela experiência sensível. Ela afirma ser necessário reconhecer a existência de uma continuidade que vai da matéria até a luz, ou seja, as imagens que aparecem são projeções luminosas e têm uma substancialidade que é feita de luz e a sua matéria é a luz. Assim, matéria e luz são as duas substâncias constitutivas do mundo terrestre ${ }^{11}$.

Por meio do exame da luz, constata-se que tudo é material, mas em graus diferentes de materialidade, razão pela qual pode se estabelecer correlação entre o que é sólido, fluido e gasoso na natureza e a constituição dos componentes essenciais do ser humano: corporeidade, psiquismo e espiritualidade. Trata-se de símbolos ou analogias, o gás e a luz, por exemplo, são símbolos do espírito, mas a semelhança não é só exterior; na verdade algumas formas constitutivas da matéria e alguns movimentos fundamentais caracterizam ontologicamente toda a realidade. ${ }^{12}$

Por essas concepções, Conrad-Martius critica o mecanicismo rígido da física galileana e newtoniana, que perde de vista a "vida" da natureza, e retorna à compreensão aristotélica do cosmos, recuperando a visão orgânica e abrindo para o entrelaçamento fecundo entre a ciência e a metafísica. Essa também é uma posição original da bióloga, pois considerando válidas as teorias científicas como instrumentos de interpretação dos fenômenos físicos - mesmo considerando-os parciais e insuficientes - sabe, porém, que não se pode prescindir de uma explicação global de tipo metafísico.

Portanto, o seu interesse pela vida da natureza, a faz retornar ao "mundo-da-vida", para compreender a globalidade da vida do cosmos, não só em termos naturalistas, mas também metafísicos. Assim seu objetivo é traçar as conexões íntimas da vida da natureza, procurando, a partir do seu interior, chegar ao processo vital e ao dinamismo profundo do real. Sua intenção é olhar a realidade global da vida da natureza, com diferentes abordagens, para descrever suas estruturas.

Com esse propósito Conrad-Martius se defronta com a questão global da origem da vida, ou seja, com as teses evolucionistas. Em muitos aspectos toma posição a favor dessas, mas também neste caso apresenta suas ideias originais.

\section{A TEORIA DO EVOLUCIONISMO E A POSIÇÃO DE HEDWIG CONRAD-MARTIUS E EDITH STEIN}

Darwin o criador da teoria do evolucionismo, chega através de suas experiências a formular a teoria da descendência, procurando explicar de onde descendem as espécies.

\footnotetext{
${ }^{10}$ ALES BELLO, A. A fenomenologia do ser humano, p. 98.

${ }^{11}$ ALES BELLO, A. A fenomenologia do ser humano, p. 106.

${ }^{12}$ ALES BELLO, A. A fenomenologia do ser humano, p. 99-100.
} 
Para ele, tanto os homens quanto os macacos têm um antepassado comum, ou seja, um primata, que em termos práticos é um ser de quatro mãos, quatro patas, pelos, rabo e orelhas pontudas. Avançando em seus estudos e viagens, vê animais diferentes, que nunca tinha conhecido antes. Encontra fósseis e constata que algumas espécies se extinguiram, mas outras continuam existindo. Elabora questionários e os envia para que criadores de cavalos e jardineiros os respondam e certifica-se de que os homens fazem cruzamentos e enxertos. Averigua que os seres humanos são capazes de transformar a natureza.

A partir disso, Darwin que é um naturalista e descreve o que encontra, formula sua teoria da seleção natural e adaptação. Depois decide enfrentar a origem do homem, na tentativa de encontrar a origem das espécies. Com a teoria da descendência, chega à conclusão de que na origem existia um pequeno molusco que se transformou em peixe, depois em anfíbio e por fim em animal. Nesse mecanismo, processa-se uma cadeia evolutiva, na qual a espécie progride da inferior para a superior. No entanto, não consegue avançar em suas pesquisas e constata que nessa cadeira evolutiva há um elo perdido, que se encontrado talvez possa explicar a origem do homem.

Conrad-Martius é contrária à interpretação mecanicista da teoria darwinista, assim como Stein que admite que haja uma transformação e evolução na natureza, mas se coloca contra essa corrente, de um modo contundente. Na interpretação de Stein, a corrente mecanicista é muito simplista, por isso questiona:

Surge agora a pergunta sobre a possibilidade do nascimento das espécies uma da outra. Essa nos parece equivalente à possibilidade de uma modificação da forma e, ao mesmo tempo, à possibilidade de um nascimento de formas. Encontramos, no indivíduo, a forma como realidade que o configura a partir do interno e o faz aquilo que é. Propriamente a forma parece a coisa imutável, que [...] determina o curso mesmo das mudanças. A espécie vegetal ou animal nos pareceu ser uma "forma universal", "o mesmo" princípio formativo em uma série de indivíduos. Como devemos entender a "universalidade" e a "singularidade" (Selbigkeit) da espécie? ${ }^{13}$

"O fenômeno científico de onde parte para discutir o problema da criação é o da presença de formações genéticas totalmente novas e não determinadas por outras precedentes, como foi muitas vezes constatado no decorrer da pesquisa científica" ${ }^{14}$. Isso se embate com a concepção de que todas as vidas teriam origem numa primeira formação. Porém, segundo Conrad-Martius, isso seria válido só se originalmente houvesse uma pluralidade de criações. Ainda, levando em consideração que a criação se refere tanto a matéria quanto a forma, no caso de uma pluralidade de criação também haveria uma nova matéria. Na opinião da bióloga "se trataria da assunção de uma nova forma por parte de uma matéria já existente, em todo caso, de uma intervenção muito radical, quase como o primeiro ato criativo"15

Isso, portanto, justifica as contínuas intervenções criativas, ou seja, os saltos do desenvolvimento dos organismos, que nem os evolucionistas conseguem explicar. Assim, ao evolucionismo tradicional, Conrad-Martius propõe um novo evolucionismo que chama de potências transfísicas. Há um logos da espécie que é uma última determinação transfísica. Não significa um desenvolvimento vital absoluto, como um fluxo de vida autocriativo, mas são substâncias que vivem e trazem em si mesmas a vida. Então, "a

${ }^{13}$ STEIN, E. La Struttura della Persona Umana, p. 105.

${ }^{14}$ ALES BELLO, A. A fenomenologia do ser humano, p. 119.

${ }^{15}$ STEIN, E. La Struttura della Persona Umana, p. 120. 
natureza viva pode realizar qualquer passo livre, segundo uma espécie de criatividade imanente, apesar de sempre previstos por Deus e realizados com o seu concurso"16

Explica Conrad-Martius, que à ideia de que há uma única raiz, como uma árvore genealógica da qual saem todos os gêneros e espécies deve ser substituída por uma imagem de um terreno no qual se encontram raízes próximas umas das outras, de onde desenvolvem diversas famílias. Dessa concepção é possível explicar as descontinuidades, os saltos e as mutações da natureza, superando a visão puramente natural e assumindo a dimensão transfísica, ou seja, a natureza não tem só uma constituição física, mas tem também o elemento que dá vida à natureza que é composto pela energia (força) e pela enteléquia, que é uma forma interior que se desenvolve, ou ainda, que é um aspecto essencial, uma forma singular própria que age em cada ser, consentindo-lhe o desenvolvimento da sua natureza.

A teoria de Darwin parece não considerar a enteléquia e nesta direção Stein, que desenvolve estudos sobre a ontologia material e formal dos seres, dá uma contribuição e explica que não é possível derivar da matéria a multiplicidade qualitativa e, por isso, é impensável um início de vida em uma natureza precedente inanimada, sem a intervenção do princípio formativo. Desse modo, não são todos os materiais, que se verificam de modo factual, que consegue explicar exaustivamente a teoria da descendência.

Para Stein, as espécies têm uma forma interna, um princípio indeterminante, que é um princípio vital, também concebido como alma, que não é abordado pelos dados adquiridos da teoria evolucionista. Além do mais, essa teoria não explica a singularidade do indivíduo e para ela, é por meio da singularidade que se consegue abarcar o que é ser humano.

Também Conrad-Martius afirma que não se pode dizer que a evolução se dá em forma de cadeia evolutiva, no qual um anel da cadeia é determinado pelo que veio anteriormente. Acontecem na natureza saltos qualitativos, pois houve, contemporaneamente, na história da natureza, a presença de dinossauros e mamíferos. Também os evolucionistas, que vieram depois de Darwin, afirmaram que espécies mais fortes eliminaram as mais fracas num processo de seleção natural e, hoje, constata-se que não se pode absolutizar a teoria do evolucionismo, pois existem as formas cooperativas na natureza.

Stein é favorável às posições de Conrad-Martius e diz que há uma grande quantidade de material advindos da experiência que demonstra que o nascimento da espécie provém de espécies anteriores, mas não há uma exclusividade nisso. A experiência também demonstra que não existem só elementos seletivos, mas também elementos de solidariedade.

Para Conrad-Martius como para Stein, o evolucionismo deve ser visto como uma teoria interpretativa e não como uma verdade, pois nem todo o material verificado pela experiência conseguiu comprovar a teoria da descendência. Assim como o filósofo não está isento de erros e enganos e a experiência pode ajudá-lo, também a intuição sobre a essência pode ajudar a superar erros advindos da experiência. ${ }^{17}$

Portanto, em conexão com o mundo vivo e com a história da natureza, situa-se o cenário para interpretar o ser humano de modo que aceitar ou não o evolucionismo não é questão secundária, e as modalidades de diferenciação entre o ser humano e a natureza são determinantes para compreender o mundo humano.

Essa compreensão alargada do evolucionismo e da história da natureza é que possibilita uma conexão entre a física e a metafísica, ou seja, além da matéria, há uma

${ }^{16}$ STEIN, E. La Struttura della Persona Umana, p. 120.

${ }^{17}$ STEIN, E. La Struttura della Persona Umana, p. 116. 
vitalidade inerente na natureza, uma força, que não é igual em todos os seres, mas que lhe dá vida e que exige uma compreensão que está além da física. Essa compreensão é que permite avançar da matéria para a constatação da existência da alma e do espírito presentes no ser humano.

\section{REFERÊNCIAS}

ALES BELLO, Angela. A fenomenologia do ser humano: traços de uma filosofia no feminino. Bauru: EDUSC, 2000.

ALES BELLO, Angela. Presentazione. In: STEIN, Edith. La Struttura della Persona Umana. Roma: Città Nuova Editrice, 2000. (Original de 1932-1933).

ALES BELLO, Angela. L'universo nella coscienza: introduzione alla fenomenologia di Edmund Husserl, Edith Stein, Hedwig Conrad-Martius. Pisa: Edizioni ETS, 2003.

ALES BELlo, Angela. Prefazione. In: STEIN, Edith. Potenza e Atto: studi per una filosofia dell'essere. Roma: Città Nuova, 2003. (Original de 1931).

ALES BELLO, Angela. Fenomenologia e Ciências Humanas. Bauru: EDUSC, 2004.

STEIN, Edith. Psicologia e Scienza dello Spirito: Contributi per una fondazione filosofica. 2. ed. Roma: Città Nuova, 1999. (Original de 1922).

STEIN, Edith. La Struttura della Persona Umana. Roma: Città Nuova, 2000. (Original de $1932-$ 1933).

STEIN, Edith. Introduzione alla Filosofia. Roma: Città Nuova, 2001. (Original de 1932-1933).

STEIN, Edith. Potenza e Atto: studi per una filosofia dell'essere. Roma: Città Nuova, 2003. (Original de 1931).

Recebido em: 17/11/2016

Aprovado em: 08/05/2017

Adair Aparecida Sberga

Rede Salesiana de Escolas

SHCS Cr Qd. 506, Bloco B, Loja 65/66 - Asa Sul

70350-525 - Brasília - DF - Brasil 